BUDGETING : Journal of Business, Management and Accounting

Volume 2, Nomor 2, Januari-Juni 2021

e-ISSN: 2715-2480

p-ISSN: $2715-1913$

DOI: https://doi.org/10.31539/budgeting.v2i2.1748

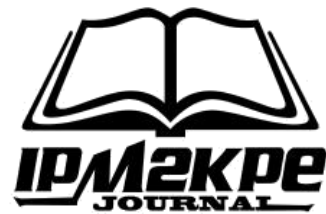

\title{
KEPUTUSAN PEMBELIAN BERDASARKAN PROMOSI DAN CITRA MEREK
}

\author{
Reza Aditya Nurmada ${ }^{1}$, Kokom Komariah' ${ }^{2}$, Asep M. Ramdan ${ }^{3}$ \\ Universitas Muhammadiyah Sukabumi ${ }^{1,2,3}$ \\ Rezanurmada1@gmail.com ${ }^{1}$
}

\begin{abstract}
ABSTRAK
Tujuan penelitian ini adalah untuk mengetahui promosi dan citra merek terhadap keputusan pembelian pada CV. Neptuns Kota Sukabumi. Metode penelitian yang digunakan oleh penulis dalam penelitian ini menggunakan metode sistem random sampling dimana penulis menyebarkan kuisioner terhadap 80 konsumen. Hasil penelitian menggunakan uji koefesien determinasi menunjukan nilai Adjuster $\left(\mathrm{R}^{2}\right)$ adalah sebesar 0,517 yang berarti pengaruh promosi dan citra merek terhadap keputusan pembelian adalah $52,9 \%$ dan $47,1 \%$ lainnya dipengaruhi oleh faktor lain yang tidak diteliti. Selain itu, pengujian koefesien korelasi ganda menunjukan nilai R sebesar 0,728 yang berarti terjadi hubungan yang kuat antara promosi dan citra merek terhadap keputusan pembelian. Berdasarkan hasil uji $\mathrm{F}$ yang telah dilakukan, ditemukan nilai Sig. adalah sebesar $0,000<0,05$. Simpulan, promosi dan citra merek berpengaruh secara positif dan signifikan secara bersama-sama terhadap keputusan pembelian.
\end{abstract}

Kata Kunci: Citra Merek, Keputusan Pembelian, Promosi

\begin{abstract}
The purpose of this study was to determine the promotion and brand image of purchasing decisions at CV. Neptuns Sukabumi City. The author's research method in this study uses a random sampling system method where the authors distribute questionnaires to 80 consumers. The study results using the coefficient of determination test showed that the Adjuster (R2) value was 0.517, which means that the effect of promotion and brand image on purchasing decisions was $52.9 \%$ and the other $47.1 \%$ were influenced by other factors not examined. Besides, the multiple correlation coefficient tests show an $R$-value of 0.728 , which means a strong relationship between promotion and brand image on purchasing decisions. Based on the F test results that have been carried out, it was found that the Sig value. is equal to $0.000<0.05$. In conclusion, promotion and brand image has a positive and significant effect together on purchasing decisions.
\end{abstract}

Keywords: Brand Image, Purchase Decision, Promotion 


\section{PENDAHULUAN}

Pakaian merupakan salah satu kebutuhan yang harus dipenuhi oleh setiap individu, sehingga perkembangan industri pakaian (fashion) setiap tahunnya semakin meningkat. Industri pakaian di Indonesia semakin berkembang karena kehadiran pabrikpabrik konveksi dan home industry yang sama-sama ditopang oleh kemajuan teknologi dan seni desain. Perkembangan ini menjadikan masyarakat menjadi lebih kreatif dalam menentukan gaya hidupnya karena memperbaiki penampilan sangatlah penting bagi kalangan semua orang. Fashion juga merupakan model hidup seseorang yang bisa menjadikan sebuah karakter gaya hidup manusia. Gaya hidup sangat erat hubungannya dengan fashion karena akan menunjang penampilan seseorang agar lebih menarik dan menjadi eksis dikalangan masyarakat (Hendariningrum, 2008).

CV. Neptune merupakan salah satu perusahaan industri kreatif di bidang fashion yang memiliki karyawan sebanyak 32 orang. Berdasarkan hasil observasi peneliti, perusahaan ini memiliki masalah pada keputusan pembelian konsumen. Permasalahan ini dapat terjadi diduga karena kurang baiknya perusahaan dalam mempromosikan produk (periklanan), sehingga konsumen enggan mengetahui produk CV. Neptuns. Adapun penyebab lainnya diduga disebabkan oleh citra merek yaitu dari brand identity yang kurang terkenal, sehingga daya beli konsumen menjadi menurun. Hal ini juga menjadikan konsumen tidak mengenal baik CV. Neptuns.

Menurut Tambunan (2016) kegiatan promosi yang berupa advertising, sales promotion dan personal selling dapat mempengaruhi konsumen dalam mengambil keputusan untuk membeli suatu produk dan mendongkrak penjualan. Selain itu, menurut Kotler \& Keller (2016) keputusan pembelian adalah bentuk pemilihan dan minat untuk membeli merek yang paling disukai diantara sejumlah merek yang berbeda. Oleh karena itu, peneliti tertarik untuk menganalisis pengaruh promosi dan citra merek terhadap keputusan pembelian oleh konsumen pada CV. Neptuns Kota Sukabumi. Penelitian ini bertujuan untuk mengukur pengaruh promosi dan citra merek terhadap keputusan pembelian pada CV. Neptuns Kota Sukabumi. 


\section{KAJIAN TEORI}

\section{Promosi}

Promosi ialah serangkaian kegiatan untuk mengkomunikasikan, memberi pengetahuan dan menyakinkan orang tentang suatu produk agar ia mengakui kehebatan produk tersebut, membeli dan memakai produk tersebut, juga mengikat pikiran dan perasaannya dalam suatu wujud loyalitas terhadap produk (Suryadi, 2011). Menurut Kotler \& Amstrong (2008) dimensi-dimensi dari promosi terdiri dari: 1) advertising (periklanan), yaitu bentuk komunikasi yang dilakukan pemasar untuk menginformasikan, dan membujuk pasar dan target pasaran; 2) sales promotion (promosi penjualan), yaitu insentif jangka panjang yang ditawarkan kepada pelanggan ataupun masyarakat dan perantara untuk merangsang datangnya pembelian produk tersebut; 3) public relations (hubungan masyarakat), yaitu usaha atau upaya untuk menarik perhatian yang positif dari masyarakat terhadap perusahaan tersebut serta produk-produknya dengan adanya berita baru, konferensi pers di event-event tertentu, melaksanakan kegiatan-kegiatan yang dapat menarik perhatian para masyarakat; 4) direct marketing (pemasaran langsung), yaitu suatu bentuk promosi secara langsung dengan cara memasarkan produk atau barang agar mendapatkan reaksi secara langsung dari konsumen.

\section{Citra Merek}

Menurut Schiffman \& Kanuk (2007) citra merek adalah sekumpulan asosiasi mengenai suatu merek yang tersimpan dalam benak atau ingatan konsumen. Wijaya (2011) menyimpulkan bahwa dimensi-dimensi utama yang mempengaruhi dan membentuk citra sebuah merek adalah sebagai berikut: 1) brand identity atau identitas fisik yang berkaitan dengan merek atau produk tersebut sehingga konsumen mudah mengenali dan membedakannya dengan merek atau produk yang lain seperti logo, warna, kemasan, lokasi, identitas perusahaan yang memayunginya, slogan dan lain-lain; 2) brand personality, yaitu karakter khas sebuah merek yang membentuk kepribadian tertentu sebagaimana layaknya manusia, sehingga konsumen dapat dengan mudah membedakannya dengan merek lain dalam kategori yang sama.

Selanjutnya, 3) brand association, yaitu hal-hal spesifik yang pantas atau selalu dikaitkan dengan suatu merek; 4) brand attitude \& behavior, yaitu sikap atau perilaku 
komunikasi dan interaksi merek dengan konsumen dalam menawarkan benefit-benefit dan nilai yang dimilikinya; 5) brand benefit \& competence, merupakan nilai-nilai dan keunggulan khas yang ditawarkan oleh suatu merek kepada konsumen yang membuat konsumen dapat merasakan manfaat karena kebutuhan, keinginan, mimpi dan obsesinya terwujudkan oleh apa yang ditawarkan tersebut.

\section{Keputusan Pembelian}

Menurut Schiffman \& Kanuk (2007) keputusan pembelian adalah pemilihan dari dua atau lebih alternatifpilihan keputusan pembelian, artinya bahwa seseorang dapat membuat keputusan, harus tersedia beberapa alternatif pilihan. Keputusan untuk membeli dapat mengarah pada bagaimana proses dalam pengambilan keputusan tersebut itu dilakukan. Menurut Kolter \& Keller (2012) terdapat enam dimensi keputusan pembelian, yaitu terdiri dari: 1) pilihan produk, dalam hal ini perusahaan harus memusatkan perhatiannya kepada orang-orang yang berniat membeli sebuah produk serta alternatifnya yang mereka pertimbangan; 2) pilihan merek, konsumen harus menjatuhkan pilihan pada merek apa yang akan dibeli. Dalam hal ini perusahaan harus mengetahui bagai mana cara konsumen menjatuhkan pilihan terhadap sebuah merek diantaranya ketertarikan pada merek, kebiasaaan pada merek, kesesuaian harga.

Selanjutnya, 3) pilihan penyalur, konsumen harus menentukan penyalur mana yang akan dipilih untuk membeli produk. Dalam hal ini konsumen memilih penyalur dapat dikarekanan faktor lokasi terdekat, harga yang murah, tersedianya barang yang lengkap dan kenyamanan pada saat membeli; 4) jumlah pembelian, konsumen dapat menentukan kuantitas barang yang akan dibeli. Dalam hal ini perusahaan harus mempersiapkan banyaknya produk yang sesuai dengan keinginan onsumen yang berbeda-beda karena konsumen akan menentukan keputusan jumlah pembelian, keputusan pembelian untuk persediaan; 5) waktu pembelian, ditentukan berdasarkan kesesuaian dengan kebutuhan, keuntungan yang dirasakan dan alasan pembelian; 5) metode pembayaran, konsumen dapat menentukan metode pembayaran yang akan digunakan pada saat transaksi pembelian. Konsumen dapat menggunakan cara pembayaran seperti bayar tunai, cek, kartu kredit, kartu debit, kartu ATM, kredit melalui lembaga keunangan dan kredit melalui toko. 


\section{METODE PENELITIAN}

Penelitian ini dilaksanakan di CV. Neptuns Kota Sukabumi dengan menggunakan metode sampling dengan teknik samplingnya yaitu simple random sampling dan melakukan penyebaran kuesioner terhadap 80 konsumen CV. Neptuns Kota Sukabumi. Teknik analisis yang digunakan dalam penelitian ini yaitu teknik analisis regresi berganda dan melakukan pengujian hipotesis secara simultan (Uji F).

\section{HASIL PENELITIAN}

\section{Hasil Analisis Regresi Linear Berganda}

Regresi linear berganda berguna untuk meneliti seberapa besar pengaruh beberapa variabel yang berkorelasi dengan variabel yang diuji. Berikut ini merupakan hasil dari regresi linear berganda yang ditunjukan pada tabel 1:

Tabel 1.

Hasil Uji Regresi Linear Berganda

\begin{tabular}{|c|c|c|c|c|c|c|}
\hline \multicolumn{7}{|c|}{ Coefficients $^{\mathrm{a}}$} \\
\hline & \multirow{2}{*}{ Model } & \multicolumn{2}{|c|}{ Unstandardized Coefficients } & \multirow{2}{*}{$\frac{\text { Standardized Coefficients }}{\text { Beta }}$} & \multirow{2}{*}{$\mathbf{t}$} & \multirow{2}{*}{ Sig. } \\
\hline & & B & Std. Error & & & \\
\hline \multirow{3}{*}{1} & $($ Constant $)$ & 8.364 & 1.591 & & 5.256 & .000 \\
\hline & $\mathrm{X} 1$ & .494 & .139 & .413 & 3.560 & .001 \\
\hline & $\mathrm{X} 2$ & .423 & .134 & .367 & 3.161 & .002 \\
\hline
\end{tabular}

a. Dependent Variable: Y

(Sumber: Data Primer (Kuesioner), 2019)

Berdasarkan hasil uji regresi linear berganda di atas, dapat diperoleh persamaan sebagai berikut :

$$
Y=8,364+0,494 X_{1}+0,423 X_{2}
$$

\section{Koefesien Determinasi $\left(\mathbf{R}^{2}\right)$}

Tabel 2.

Hasil Koefesien Determinasi

\begin{tabular}{ccccc}
\hline \multicolumn{5}{c}{ Model Summary } \\
\hline Model & $\mathbf{R}$ & R Square & Adjusted R Square & Std. Error of the Estimate \\
\hline 1 & $.728^{\text {a }}$ & .529 & .517 & 2.181 \\
\hline a. Predictors: (Constant), X2, X1 & & \\
\hline (Sumber: Data Primer (Kuesioner), 2019) & &
\end{tabular}

Hasil tabel 2 menunjukan bahwa besarnya nilai Adjusted $\mathrm{R}^{2}$ adalah 0,517; Hal tersebut menunjukan $51,7 \%$ variabel keputusan pembelian dapat dijelaskan oleh kedua 
variabel independen yaitu promosi dan citra merek sementara $47,1 \%$ berasal dari faktor yang tidak diteliti dalam penelitian.

\section{Koefesien Korelasi Ganda (R)}

Tabel 3.

Hasil Koefesien Korelasi Ganda

\begin{tabular}{ccccc}
\hline \multicolumn{5}{c}{ Model Summary } \\
\hline Model & R & R Square & Adjusted R Square & Std. Error of the Estimate \\
\hline 1 & $.874^{\text {a }}$ & .763 & .757 & 1.987 \\
\hline a. Predictors: (Constant), Word of Mouth (X2), Keunikan Produk (X1) & \\
\hline \multicolumn{4}{l}{ (Sumber: Data Primer (Kuesioner), 2019) }
\end{tabular}

Berdasarkan tabel 3 di atas, diperoleh angka $\mathrm{R}$ sebesar 0,874 yang berada pada kategori 0,80-1,000. Hal ini menunjukan bahwa hubungan yang terjadi antara promosi dan citra merek dengan keputusan pembelian terbilang sangat kuat.

\section{Uji Signifikasi Secara Simultan (Uji F)}

Tabel 4.

\section{Hasil Uji F}

\begin{tabular}{cllcccc}
\hline \multicolumn{8}{c}{ Model Summary } \\
\hline \multirow{3}{*}{1} & Model & Sum of Square & df & Mean Square & F & Sig. \\
\cline { 2 - 7 } & Regression & 917.553 & 2 & 458.777 & 116.214 & $.000^{\mathrm{b}}$ \\
\cline { 2 - 7 } & Residual & 284.233 & 72 & 3.948 & & \\
\cline { 2 - 7 } & Total & 1201.787 & 74 & & & \\
\hline
\end{tabular}

a. Dependent Variable: Keputusan Pembelian (Y)

b. Predictors: (Constant), Word of Mouth (X2), Keunikan Produk (X1)

(Sumber: Data Primer (Kuesioner), 2019)

Berdasarkan tabel 4 di atas, hasil uji F yang dilakukan menunjukkan bahwa nilai sig. $0,000<0,05$; nilai $F_{\text {hitung }} 43.318>F_{\text {tabel }}$ 3,96. Hasil ini memperlihatkan bahwa promosi dan citra merek berpengaruh secara simultan terhadap keputusan pembelian.

\section{PEMBAHASAN}

Promosi dan citra merek berpengaruh positif dan signifikan terhadap keputusan pembelian secara simultan. Hal ini dibuktikan dengan hasil pengujian $F$ yang menunjukkan nilai signifikansi adalah sebesar 0,000 $(<0,05)$; nilai $F_{\text {hitung }} 43.318>F_{\text {tabel }}$ 3,96. Hal ini membuktikan bahwa permasalahan pada keputusan pembelian yang terjadi pada CV. Neptuns sangat dipengaruhi oleh promosi dan citra merek. Promosi yang 
diterapkan di perusahaan belum begitu maksimal sehingga membuat konsumen kurang berminat membeli produk dan citra merek dari brand identity perusahaan ini juga kurang terkenal.

Hasil yang ditemukan pada penelitian ini sejalan dengan hasil penelitian Nurmiyati (2009) bahwa variabel-variabel citra merek, kualitas produk dan promosi penjualan mampu meningkatkan citra perusahaan secara signifikan. Menurut Permana (2017) promosi memiliki pengaruh positif dan signifikan terhadap keputusan pembelian, dimana promosi berdampak positif terhadap peningkatan keputusan pembelian. Adapun pengaruh citra merek terhadap keputusan pembelian menurut Suciningtyas (2012) adalah mempunyai pengaruh yang positif. Semakin tinggi brand image yang diciptakan oleh perusahaan, maka tingkat pengambilan keputusan untuk membeli juga semakin meningkat.

Menurut Dane et al., (2013) promosi tidak hanya memperkenalkan suatu produk atau keunggulan pada produk tersebut, namun kegiatan promosi juga dimaksudkan untuk dapat berkomunikasi dengan konsumen, sehingga perusahaan dapat memperkenalkan, membujuk, mempengaruhi, maupun mendorong konsumen untuk membeli produk maupun jasa yang telah ditawarkan perusahaan pada konsumen. Hal ini ini sangat bermanfaat untuk membangun citra brand pada perusahaan tentang persepsi konsumen pada suatu produk. Hal ini berarti semakin tinggi citra brand maka semakin tinggi tingkat keputusan pembelian yang berlanjut (Apriyani, 2013).

\section{SIMPULAN}

Promosi dan citra merek berpengaruh positif dan signifikan secara simultan terhadap keputusan pembelian pada CV. Neptuns Kota Sukabumi.

\section{DAFTAR PUSTAKA}

Apriyani, Y. (2013). Pengaruh Brand Image, Harga dan Kualitas Pelayanan terhadap Keputusan Pembelian Ulang Pizza Hut di Kota Padang. Jurnal Manajemen, 2(1), 1-10

Dane, N., Sukaatmadja, I. P. G., \& Budiasa, I. W. (2013). Analisis Pengaruh Biaya Promosi terhadap Nilai Penjualan Produk pada UD. Kopi Bali Banyuatis, Singaraja. Jurnal Manajemen Agribisnis, 1(1), 1-15

Hendariningrum, R. (2008). Fashion dan Gaya Hidup: Identitas dan Komunikasi. Jurnal Ilmu Komunikasi UPNYK, 6(1), 25-32 
Kotler, P., \& Keller, K. L. (2012). Manajemen Pemasaran Jilid I Edisi Ke 12. Jakarta: Erlangga

Kotler, P., \& Keller, K. L. (2016). Marketing Management, 15th Edition. New Jersey: Pearson Pretice Hall, Inc

Kotler, P., Armstrong, G. (2008). Prinsip-prinsip Pemasaran, Jilid 1. Jakarta: Erlangga

Nurmiyati, N. (2009). Analisis Pengaruh Citra Merek, Kualitas Produk dan Promosi Penjualan terhadap Citra Perusahaan (Studi pada CV. Aneka Ilmu Cabang Cirebon). Tesis. Universitas Diponegoro

Permana, D. I. (2017). Pengaruh Promosi terhadap Keputusan Pembelian Produk Lantai Kayu dan Pintu PT. Piji di Jawa Timur. Performa: Jurnal Manajemen dan StartUp Bisnis 2(1), 116-123

Schiffman, L. G., \& Kanuk, L. L. (2007). Consumer Behavior. New Jersey: Perason Prestice Hall

Suciningtyas, W. (2012). Pengaruh Brand Awareness, Brand Image dan Media Komunikasi terhadap Keputusan Pembelian. Management Analysis Journal, l(1), 1-8

Suryadi, D. (2011). Promosi Efektif Menggugah Minat \& Loyalitas Pelanggan. Jakarta: PT. Suka Buku

Tambunan, J. (2016). Pengaruh Bauran Promosi terhadap Keputusan Pembelian Panorama Motor. Skripsi. Universitas Ciputra 